\title{
Tardive dyskinesia - how is it prevented and treated?
}

\author{
Denise Duncan, Harry McConnell and David Taylor
}

Tardive dyskinesia (TD), literally meaning a late occurring, abnormal movement disorder, was first described by Schonecker in 1957, about five years after the discovery of chlorpromazine (cited in Kane, 1992). TD generally occurs after long-term antipsychotic therapy: Kane et al (1984) reported that the incidence was increased with each subsequent year of exposure to antipsychotics, starting with an incidence of $5 \%$ after one year of exposure and increasing by $5 \%$ each subsequent year. Certainly, the prevalence of TD has increased over the last 20 years, probably as the result of more patients being exposed to antipsychotics for longer periods.

TD is commonly characterised by lip smacking and chewing, often with episodic tongue protrusion ("fly-catching") or pushing the tongue into the inner cheek or lip. Grimacing and other facial muscle movements can occur forming the buccolingual masticatory syndrome. Other abnormal movements which can appear include choreiform movements of the hands ("piano-playing"), pelvic-thrusting or rocking of the legs. In severe TD, there may be problems with speaking and eating as well as difficulty in breathing and swallowing. The movements seen in TD are involuntary, although patients may be able to suppress their occurrence for short periods. Tardive dystonia, akathisia, Tourette's, myoclonus and other syndromes have also been described.

It has been postulated that TD develops as a result of dopamine receptor blockade, leading to supersensitivity of the postsynaptic dopamine receptors. Certainly, similarities exist between TD symptomatology and levodopainduced dyskinesias seen in Parkinson's disease, and TD symptoms often resolve on increasing the dose of antipsychotic, while decreasing the antipsychotic dose can lead to exacerbations. Also, dopamine agonists may increase TD symptoms. However, this dopamine supersensitivity can occur within weeks of starting an antipsychotic, whereas TD does not usually become evident for months or years. A hypernoradrenergic state, deficiency in gamma-aminobutyric acid (GABA), as well as involvement of serotonin, free radicals, neuropeptides and numerous other hypotheses have been proposed (see review of Lohr \& Jeste. 1992).

As there have been no proven safe and effective treatments for TD, the most important step is to prevent its development (Table 1). Once signs of TD are evident, management will often depend on the underlying psychiatric illness. If the patient does not have a psychotic illness, drugs other than antipsychotics should be tried. In those with schizophrenia or other psychoses, treatment becomes more complicated. The antipsychotic dose should be slowly decreased over a period of several months and, if possible, stopped. As anticholinergics may exacerbate TD, they should also be discontinued, although this is still controversial (see discussion of Jeste \& Caligiuri, 1993). With discontinuation of medications, $36-55 \%$ of patients will have spontaneous improvement in their symptoms, although such improvement is often delayed and may take up to five years (Miyasaki \& Lang, 1995).

Obviously, discontinuation of antipsychotics is not possible in every patient and the risk of relapse or psychosis must be balanced against the risk of TD. In patients where antipsychotics cannot be discontinued, there is evidence that TD is not necessarily progressive in all cases (Lohr \& Jeste, 1992) and that continuation at the lowest possible dose minimises the risk of progression (Kane, 1992). One should watch for the occurrence of withdrawal dyskinesias during antipsychotic taper, but be aware that their emergence does not necessarily herald the onset of or exacerbation of TD. TD may. however, be unmasked during antipsychotic withdrawal, but this should not be a deterrent to the clinician to attempt to minimise the dose. Some earlier studies suggested that reducing cumulative neuroleptic exposure may decrease the risk of developing TD, leading to recommendations for drug holidays. There has since. however, been some evidence that repeated interruption of maintenance antipsychotic treatment may actually increase the risk of developing TD and increase psychiatric morbidity compared with continuous low dose 
Table 1. Prevention of TD

Consider risk factors (l.e. female, elderly, affective disorder, total antipsychotic dose)

Use lowest dose of antipsychotic necessary

Use antipsychotic for shortest time necessary

Reassess need for antipsychotics regularly

Reassess need for anticholinergics regularly (i.e. 3 monthly)

Consider use of antipsychotics less likely to cause TD (i.e. clozapine, ?olanzepine, ?sertindole) Avoid intermittent antipsychotic therapy

Table 2. Treatments used for TD

\begin{tabular}{|c|c|c|}
\hline Class of drug & Drug & Comments \\
\hline $\begin{array}{l}\text { Drugs acting on the } \\
\text { dopamine system }\end{array}$ & $\begin{array}{l}\text { Antipsychotics } \\
\text { Reserpine } \\
\text { Tetrabenazine } \\
\text { Oxypertine } \\
\text { Methyldopa }\end{array}$ & $\begin{array}{l}\text { Short-term efficacy; side-effects can } \\
\text { be limiting; increasing dose of } \\
\text { antipsychotics will worsen in long-term }\end{array}$ \\
\hline Cholinomimetics & $\begin{array}{l}\text { Choline } \\
\text { Deanol } \\
\text { Lecithin } \\
\text { Physostigmine }\end{array}$ & Little evidence of efficacy \\
\hline Anticonvulsants & Sodium valproate & $\begin{array}{l}\text { Some evidence of efficacy } \\
\text { and perhaps useful in prophylaxis }\end{array}$ \\
\hline Benzodiazepines & Clonazepam & $\begin{array}{l}\text { May be effective at doses of } \\
2-4.5 \mathrm{mg} / \text { day in some patients; } \\
\text { dystonic symptoms may respond } \\
\text { better than choreoathetoid } \\
\text { dyskinesias }\end{array}$ \\
\hline Other GABA agonists & $\begin{array}{l}\text { Baclofen } \\
\text { Muscimol } \\
\text { Progabide } \\
\gamma \text {-acetylenic GABA } \\
\gamma \text {-vinyl GABA (vigabatrin) }\end{array}$ & $\begin{array}{l}\text { Little evidence of efficacy for } \\
\text { baclofen; other more specific GABA } \\
\text { agonists may be more promising }\end{array}$ \\
\hline Calcium-channel blockers & $\begin{array}{l}\text { Diltiazem } \\
\text { Nifedipine } \\
\text { Verapamil }\end{array}$ & $\begin{array}{l}\text { Nifedipine ( } 40-80 \mathrm{mg} / \text { day }) \text { may } \\
\text { be more effective than others: } \\
\text { may be more effective in elderly } \\
\text { and in severe TD }\end{array}$ \\
\hline Beta-blockers & Propranolol & $\begin{array}{l}\text { Partial improvement seen in many; } \\
\text { may however be due to CYP2D6 } \\
\text { inhibition, increasing antipsychotic } \\
\text { levels; may be helpful in akathisia }\end{array}$ \\
\hline Free radical scavengers & Vitamin $\mathrm{E}$ & $\begin{array}{l}\text { Has been shown to be effective } \\
\text { in some patients in double-blind } \\
\text { placebo controlled trials }\end{array}$ \\
\hline Local parenteral agents & Botulinum toxin & $\begin{array}{l}\text { Case reports of effectiveness } \\
\text { in tardive dystonia }\end{array}$ \\
\hline Other drugs & $\begin{array}{l}\text { Amantadine } \\
\text { Apomorphine } \\
\text { Bromocriptine } \\
\text { Buspirone } \\
\text { Oestrogen } \\
\text { Opiates } \\
\text { Pyridoxine }\end{array}$ & Anecdotal reports of efficacy only \\
\hline ECT & & $\begin{array}{l}\text { Case reports of short-term efficacy. } \\
\text { but also reports of exacerbation }\end{array}$ \\
\hline
\end{tabular}

From reviews of Lohr \& Jeste, 1992; Bazire, 1996; Miyasaki \& Lang, 1995. 
treatment (see discussion of Jeste \& Caligiuri, 1993). There is thus no indication for drug holidays in the prevention of TD.

Because clozapine, olanzapine and sertindole are unlikely to cause extrapyramidal sideeffects, they may not be associated with TD. and so should be considered if an antipsychotic is required. Sulpiride and risperidone may also be somewhat less likely to cause TD than standard antipsychotics. Clozapine may even be a treatment option for TD. Lieberman et al (1991), in a review of eight published studies, examined the outcome of 30 patients with TD treated with clozapine for up to 36 montherand found a $50 \%$ or greater reduction in TD symptoms in approximately $43 \%$ of cases. Benefits were greatest in patients with severe TD, particularly tardive dystonia. Some improvement was also noted in patients with typical choreoathetoid symptoms. However, definitive conclusions could not be made due to methodological limitations.

Shapleske et al (1996) recently reported the successful treatment of tardive dystonia with clozapine and clonazepam in combination. Clozapine alone had only limited success but within two weeks of adding clonazepam ( $3 \mathrm{mg} /$ day). there was a virtually complete resolution of all abnormal movements. Moreover, this improvement was sustained at follow-up, almost two years later.

Increasing the antipsychotic dose has been suggested as a treatment option. While this may ameliorate the symptoms in the short term, it usually exacerbates them in the long term. Reserpine, tetrabenazine and other dopaminedepleting drugs have been used with some success but their side-effects (e.g. worsening of Parkinsonism, depression, sedation) often limit their usefulness. There have been anecdotal reports for efficacy of cholinomimetics, various GABA agonists, dopamine agonists and numerous other agents. There have however been very few controlled trials of these agents.

Of those agents which have been studied, Vitamin $E$ appears to diminish symptoms of TD in some patients. There have been several double-blind, placebo-controlled trials of Vitamin $E$ in doses of 800-1600 I.U./day showing some beneficial effect, particularly in patients who have had TD for five years or less (Lohr et al. 1987; Elkashef et al, 1990; Egan et al, 1992; Dabiri et al, 1994; Lohr \& Caligiuri, 1996), although this is controversial. Sideeffects include nausea, vomiting, abdominal cramps, diarrhoea, headache, fatigue and allergic reactions. Although it appears to be generally well tolerated at this stage, its efficacy, the necessary treatment duration and specific indications are not yet clearly established.

Thaker et al (1990), in a 12-week, doubleblind, placebo-controlled, randomised crossover trial, tested clonazepam in 19 patients with TD. Eighteen of the 19 patients were being treated with antipsychotics (mean chlorpromazine equivalent dose, 1291 (s.d. 1372) mg/day). Clonazepam in doses of $2-4.5 \mathrm{mg} /$ day reduced dyskinesia scores overall by $37.1 \%$. This effect was reversed with placebo administration. Clonazepam was more effective in patients with dystonic than in those with choreoathetoid symptoms. In the five patients who continued with the clonazepam long-term, after trial completion, tolerance developed to the antidyskinetic effects. Clonazepam was, however, effective again in these patients following a two-week drug-free period. This agent may thus be particularly useful for intermittent treatment such as in social situations where suppression of TD symptoms would be highly desirable.

Other drugs that have shown some promise in the treatment of TD include nifedipine. valproate, specific GABA agonists (not widely available) and botulinum toxin (for the treatment of tardive dystonia only). Although dopamine agonists as well as $\gamma$-vinyl GABA (vigabatrin) have been reported to improve TD. they may also cause psychosis as an adverse effect and cannot thus be routinely recommended in patients with psychosis and TD. Table 2 shows the various classes of drugs used in TD, and Table 3 summarises our treatment recommendations.

Table 3. Recommendations for the treatment of TD

Prevention whenever possible (see Table 1)

Withdrawal of offending agent, if possible (must be balanced against risk of relapse)

If antipsychotic necessary, consider use of clozapine or possibly sertindole; consider use of mood stabilisers alone for bipolar disorder

Withdraw anticholinergics

Consider withdrawing other drugs which may cause or exacerbate movement disorders

(metoclopramide, antidepressants, stimulants, antiparkinsonian agents; se日 Miller \& Jankovic, 1992)

Consider Vitamin E 400 I.U./day; may increase by 400 I.U. weekly to a maximum of 1600 I.U./day in divided doses

If above measures are ineffective, consider clonazepam $1 \mathrm{mg} /$ day (elderly $0.5 \mathrm{mg} /$ day), increasing over 2-4

weeks to $4.5 \mathrm{mg} / \mathrm{day}$ in divided doses; intermlttent treatment may be preferable as tolerance likely to develop 


\section{References}

Bazare, S. (ed.) (1996) Psychotropic Drug Directory 1996. Dinton. Wiltshire: Mark Allen Publishing.

DABIR, L. M., PASTA, D., DARBY, J. K., et al (1994) Effectiveness of Vitamin $\mathrm{E}$ for treatment of long-term tardive dyskinesia. American Journal of Psychiatry. 161, 925-926.

Egan, M. F., Hyde, T. M., Albers, G. W., et al (1992) Treatment of tardive dyskinesia with Vitamin $E$. American Joumal of Psychiatry, 149, 773-777.

ElKashef, A. M., RUSKIN, P. E., BACHER, N., et al (1990) Vitamin $E$ in the treatment of tardive dyskinesia. American Joumal of Psychiatry. 147, 505-506.

JESTE, D. V. \& CALIGIURI, M. P. (1993) Tardive dyskinesia. Schizophrenia Bulletin, 19, 303-315.

KANE, J. M. (1992) Tardive dyskinesia. In Movement Disorders in Neurology and Neuropsychiatry (eds A. B. Joseph \& R. R. Young) pp. 33-39. Oxford: Blackwell Scientific.

-. WOERNER, M., Weinhold, P., et al (1984) Incidence of tardive dyskinesia: five year data from a prospective study. Psychopharmacology Bulletin, 20, 387. (Cited in Miyasaki \& Lang, 1995).

Leberman, J. A., SAlTz, B. L., Johns, C. A., et al (1991) The effects of clozapine on tardive dyskinesia. British Journal of Psychiatry, 168, 503-510.

LOHR, J. B., CADET, J. L., LOHR, M. A., et al (1987) Alphatocopherol in tardive dyskinesia. Lancet. 1, 913-914.

- \& JESTE. D. V. (1992) Neuroleptic-induced movement disorders: tardive dyskinesia and other tardive syndromes. In Psychiatry. Vol. 3. (ed. R. Michels), pp. 1-17. Philadelphia: J. B. Lippincott.
- \& CALIGIUR, M. (1996) A double-blind placebo-controlled study of Vitamin $E$ treatment of tardive dyskinesia. Journal of Clinical Psychiatry. 57, 167-173.

MILLER, L. G. \& JANKOVIC, J. (1992) Drug-induced movement disorders: an overview. In Movement Disorders in Neurology and Neuropsychiatry (eds A. B. Joseph \& R. R. Young). pp. 5-32. Oxford: Blackwell Scientific.

MrYASAK, J. M. \& LANG, A. E. (1995) Treatment of druginduced movement disorders. In Treatment of Movement Disorders (ed. R. Kurlan), pp. 429-474. Philadelphia: J. B. Lippincott.

Shapleske, J., MCKay, A. P. \& MCKenNa, P. J. (1996) Successful treatment of tardive dystonia with clozapine and clonazepam. British Journal of Psychiatry, 168, 516-518.

THAKER, G. K., NGUYEN, J. A., STRAUSS, M. E., et al (1990) Clonazepam treatment of tardive dyskinesia: a practical GABAmimetic strategy. American Joumal of Psychiatry. 147. $445-451$.

Denise Duncan, Senior Drug Information Pharmacist, Maudsley Hospital; Harry McConnell, Neurology Research Fellow, Institute of Psychiatry; and "David Taylor, Chief Pharmacist, Maudsley Hospital, Denmark Hill, London SE5 8AZ

*Correspondence 